\title{
DESIGN MODIFICATION OF SEED DISTRIBUTOR OF PNEUMATIC SEEDER FOR CORN SOWING
}

\author{
Elena Zubrilina ${ }^{1}$, Lyubov Vysochkina ${ }^{2}$, Mikhail Danilov $^{2}$, Vladimir Maliyev ${ }^{2}$ \\ ${ }^{1}$ Don State Technical University, Russia; ${ }^{2}$ Stavropol State Agrarian University, Russia \\ elena-zubrilina@rambler.ru, lubasha_vis_67@list.ru, danilomaster80@mail.ru, \\ vladimir_maliev@mail.ru
}

\begin{abstract}
A feature of the pneumatic sowing machines is to mount the opener sowing apparatus. Analytical studies of serial row planters have found that the free fall of seed from the sowing apparatus to the bottom of the furrow leads to spreading seeds, both along and across the furrow. The spread worsens crop uniformity and lowers the yield. To overcome this limitation it is necessary to reduce the height and angle of the seed fall, the magnitude and direction change their speed at the time of reset. This study designed a sowing unit with seminal duct, having accelerator of seed. The regularities of seed movement in the seminal duct pneumatic sowing machine with the influence of the speed of aggregate movement are substantiated. The factors that allow the seed to reach the speed at the exit of the seminal duct, equal to the rate of seed unit are: the air speed in an accelerator, the accelerator length, the angular speed of the seed disc. The parameters and operating modes of the sowing machine, equipped with the seminal duct with the accelerator: the inner diameter of the seminal duct is $16 \mathrm{~mm}$, the height of the start and end sections of $0.14 \mathrm{~m}, 0.01 \mathrm{~m}$; the radius of curvature of the second portion of the seminal duct is $0.076 \mathrm{~m}$, the angle of descent of the seeds with the seed disc -200 , the accelerator length - 0.12 $\mathrm{m}$, the angular speed of the seed disc $2.5-3.0 \mathrm{~s}^{-1}$, the air flow rate in the accelerator $18 \ldots 20 \mathrm{~m} \cdot \mathrm{s}^{-1}$. The experimentally determined average interval between sowing seeds of corn at a pneumatic device with the seminal duct without accelerator totaled $342 \mathrm{~mm}$, with the vas deferens with the accelerator - $304 \mathrm{~mm}$; the coefficient of variation was $41.4 \%$ and $38.8 \%$; percentage of seeds at intervals in the prescribed initial requirements is respectively $52 \%$ and $92 \%$. Using of the seminal duct with the accelerator allows to manage the process of delivery of seeds from the seed unit to the bottom of the furrow with the seed feed rate at the output of up to $3.5 \mathrm{~m} \cdot \mathrm{s}^{-1}$.
\end{abstract}

Keywords: corn sowing, seed distributor, seeder, seminal duct.

\section{Introduction}

In the balance of the world corn ranks the third place after rice and wheat. The yield of corn depends largely on the quality of sowing seeds, including the placement of seeds in a row. Currently, for planting of corn pneumatic drills are used, such as "MaterMacc", "Gaspardo", "Optima", "AiST" and others. The coulter of these drills is attached directly to the sowing unit and the seeds discharged from the disk seed drill distributor fall free across from coulter to the bottom of the furrow. This planter arrangement does not provide a uniform distribution of seeds on the bottom of the furrow, especially at high speeds [1-3]. Free fall of seeds accompanied by dispersion of a landing place of seeds as along the furrow and across it reduces the yield of corn. Therefore, a seeding machine with a perfect uniform supply of seeds to exit from it cannot guarantee uniform distribution of seeds on the bottom of the furrow.

Analysis of studies of the row crop seeding process one by one has shown that the condition of the smallest dispersion of seeds along the furrow is equality of the horizontal component of the speed of the seed at the time of ejection and the motion speed of drills. As a result, the absolute speed of the seed is approximately zero and drop occurs along a trajectory close to the vertical [3-5]. Eliminating of the defects can make the process of movement of the seed drill distributor to the bottom of the furrowcontrolled, i.e. at the set trajectory and speed. Structurally, it is possible, if the motion after the seed drill distributor will be carried out by a particular form drill tube, which not only ensures a constant motion trajectory of seeds, but has the ability to change the speed of the seeds to the extent necessary with the help of the seed accelerator movement.

The purpose is improvement of the quality of sowing of row crops with pneumatic drills by installing a drill tube, ensure the control of the movement of seeds from the drill distributor to the bottom of the furrow. 


\section{Materials and methods}

To make the condition of equality of the seed speed and drill speed in the construction of the drill tube the seed accelerator was used, which provided accelerated movement of seeds in the drill tube to the required values.

The drill tube (Fig. 1) is a tube 1 circular cross section that is fixed to the seed drill distributor through the bracket 2 hose clamp 3. The drill tube has three sections: a straight I, a curvilinear II and an accelerating III. In the area No. I seeds come down from the seed disc placed on the inner surface of the trough drill tubes and slide on it as on an inclined plane to the section II. At the area No. II seeds move along the curved surface with constant radius as long as the speed vector does not acquire the horizontal direction. In the area No. III horizontally moving seeds using the air flow are accelerated to a speed equal to the largest sowing unit speed and thus zero speed is provided relative to the seeds of the soil at the moment they contact the furrow.

The dumping point of seeds from the seeding disc is chosen so that at the time of exit from the seed disc they come to the inner surface of the drill tube. In this case, they are not laid on the rebound wall of the drill tubes and slide on the inner surface.

The energy of seeds at the beginning of the movement along the surface of the vas deferens is composed of the potential energy of the seed $E_{n 0}$ located at a height $\mathrm{h}$ from the bottom of the furrow, and the kinetic energy $E_{k 0}$ of the seed coming off the rotating disk at a speed of $v_{0}$. At the exit from the drill tube, the seed acquires a final speed of the horizontal direction and possesses: the kinetic energy $E_{\kappa \kappa}$ and the potential energy $E_{n \kappa}$. When moving along the surface of the drill tube, part of the energy is expended on the work of the friction forces of the seed on the surface of the $A_{m p}$ conduit and on the work of the air resistance forces $A_{c b}$.

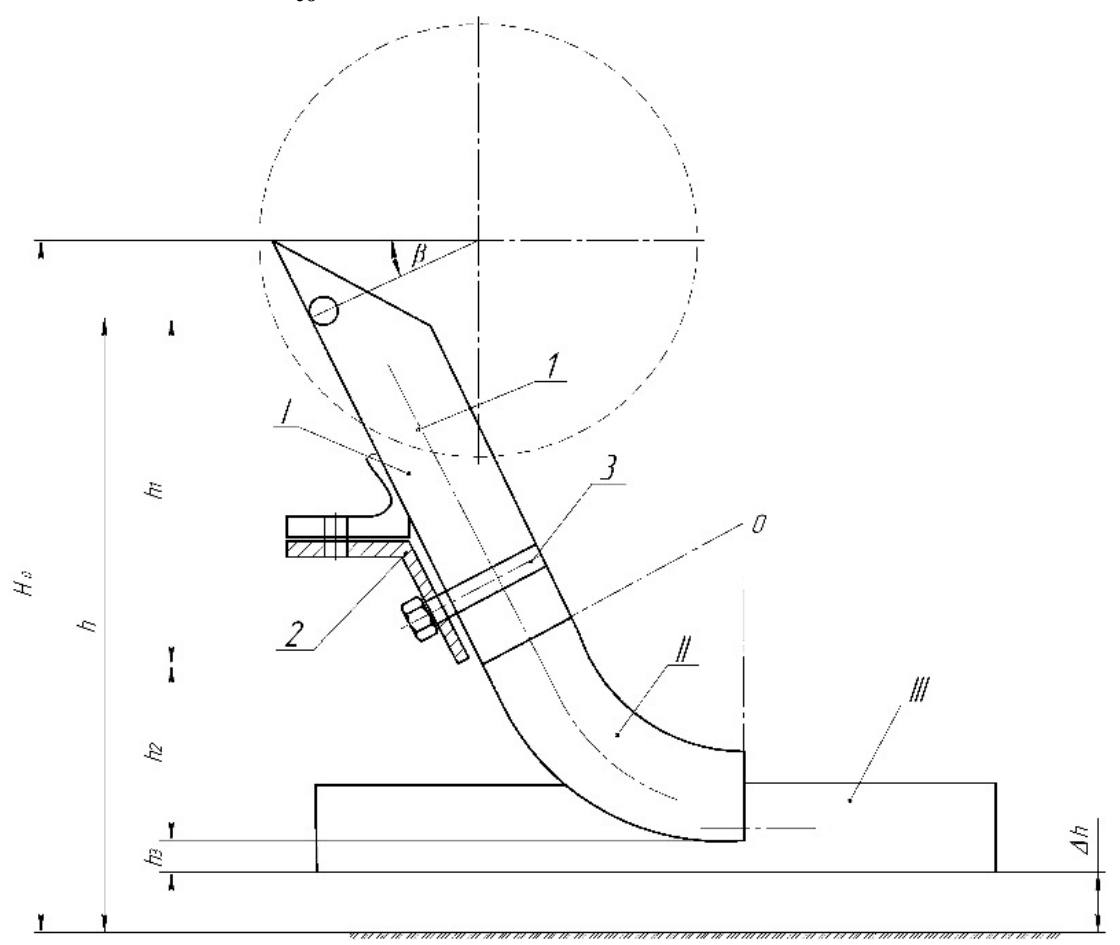

Fig. 1. Scheme of drill tube of pneumatic drill

The law of conservation of energy of the seed moving along the drill tube is described by the equation:

$$
E_{n 0}+E_{\kappa 0}=E_{n \kappa}+E_{\kappa \kappa}+A_{m p}+A_{c B} .
$$

This law is valid for any part of the drill tube. The final values of the kinematic $\left(E_{k}\right)$ and potential $\left(E_{n}\right)$ energies of the previous section are the initial values of these parameters of the subsequent section. 
A seed that has descended from the sowing disk with the speed of $v_{0}$ at an angle of $\beta_{1}$ to the vertical, enters the drill tube, is placed on the gutter-like surface of the drill tube and, under the action of its own weight, with initial velocity $v_{0}$, slides over the surface acquiring the velocity $v_{k 1}$ at the end of the site (Fig. 2).

Designated by $\Delta E_{n}$, the difference between the potential energies of the seed at the beginning of the section of $E_{n 0}$ and at the end of $E_{n \kappa}$, we can obtain the energy balance equation for area I of the drill tube

$$
E_{\kappa \kappa 1}-E_{\kappa 0}-\Delta E_{n 1}+A_{m p 1}+A_{c \varepsilon 1}=0 .
$$

Substituting the corresponding expressions and transforming the formula 2, we obtain

$$
\frac{m v_{\kappa 1}^{2}}{2}-\frac{m v_{0}^{2}}{2}-m g h_{1}+f m g \cdot \operatorname{tg} \beta \cdot h_{1}+\frac{m K_{\Pi} h_{1}\left(v_{0}+v_{\kappa 1}\right)^{2}}{4 \cos \beta}=0 .
$$

where $m$ - mass of the seed, $\mathrm{kg}$;

$h_{1}$ - geodetic level difference start and end of the area I, m;

$f$ - seed coefficient of friction of the drill tube;

$K_{\Pi}$ - coefficient of seed windage, $\mathrm{m}^{-1}$.

Solving this equation for $v_{\kappa}$, we get:

$$
\begin{gathered}
v_{\kappa 1}=\frac{-K_{\Pi} h_{1} v_{0}}{2 \cos \beta+K_{\Pi} h_{1}}+ \\
+\frac{\sqrt{K_{\Pi}^{2} h_{1}^{2} v_{0}^{2}-\left(2 \cos \beta+K_{\Pi} h_{1}\right)\left(K_{\Pi} h_{1} v_{0}^{2}+4 \sin \beta \cdot f g h_{1}-2 \cos \beta v_{0}^{2}-4 \cos \beta \cdot g h_{1}\right)}}{2 \cos \beta+K_{\Pi} h_{1}} .
\end{gathered}
$$

If the wind resistance is not taken into account, then the seed speed at the end of the arae I is determined from the dependence:

$$
v_{\kappa 1}=\sqrt{v_{0}^{2}+2 g h_{1}(1-f \cdot \operatorname{tg} \beta)} .
$$

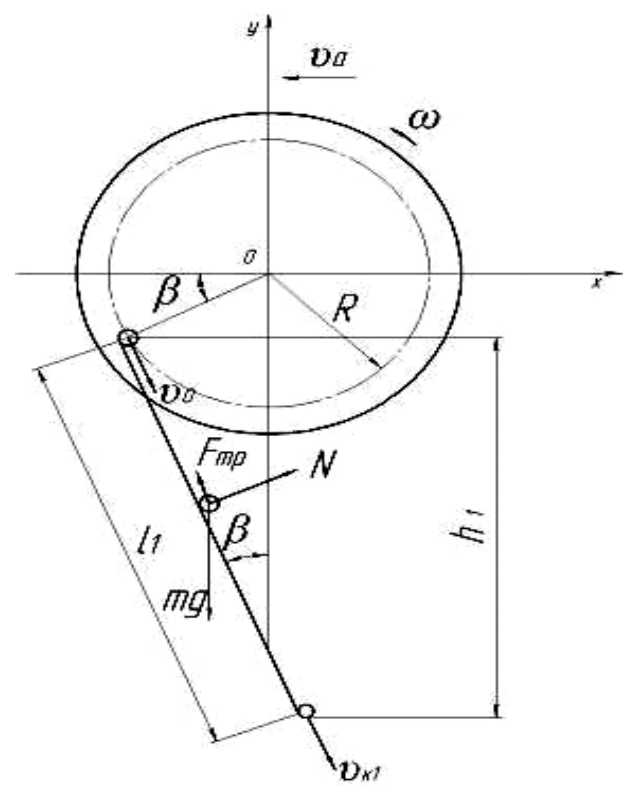

Fig. 2. Scheme of movement of the seed on the drill tube area $I$

According to the results of experimental studies: $K_{\Pi}=0,09 \mathrm{~m}^{-1} ; h_{1}=0.144 \mathrm{~m} ; \beta=20^{\circ} ; f=0.25$; $R=0.06 \mathrm{~m}$. The variable value is the angular velocity $\omega$, which at a constant radius $\mathrm{R}$ determines the value of the velocity $v_{0}$. Since $v_{0}<1$ and in the equations is present in the square, its effect on the final result is insignificant and as an assumption we take $\omega=3 \mathrm{sec}^{-1}$ 
At the area II, having a curved surface, the velocity vector changes the direction (Fig. 3) and the angle between the velocity vector and the vertical $(\varphi)$ varies in the range of up $\beta$ to $\pi / 2$.

Energy balance equation for area II of the drill tube has the form:

$$
E_{\kappa \kappa 2}-E_{\kappa 02}-\Delta E_{n 2}+A_{m p 2}+A_{c b 2}=0 \text {. }
$$

After the transformations, we obtain the expression for determining the seed velocity in the end of area II:

$$
\begin{gathered}
v_{\kappa 2}=\frac{-\alpha v_{\kappa 1}\left(f+\rho K_{\Pi}\right)}{2+\alpha \cdot f+\alpha \rho K_{\Pi}}+ \\
+\frac{\sqrt{\alpha^{2} v_{k 1}^{2}\left(f+\rho K_{\Pi}\right)^{2}-\left(2+\alpha f+\alpha \beta K_{\Pi}\right)\left(\alpha f v_{k 1}^{2}+\alpha \rho K_{\Pi} v_{k 1}^{2}+4 f \rho \cdot g \cdot \cos \beta-4 g h_{2}-2 v_{k 1}^{2}\right)}}{2+\alpha \cdot f+\alpha \rho K_{\Pi}}
\end{gathered}
$$

where $v_{i}$ - instantaneous velocity on area II of the drill tube, $\mathrm{m} \cdot \mathrm{s}^{-1}$;

$\rho$-radius of curvature of the drill tube (we assume constant over the whole area), m;

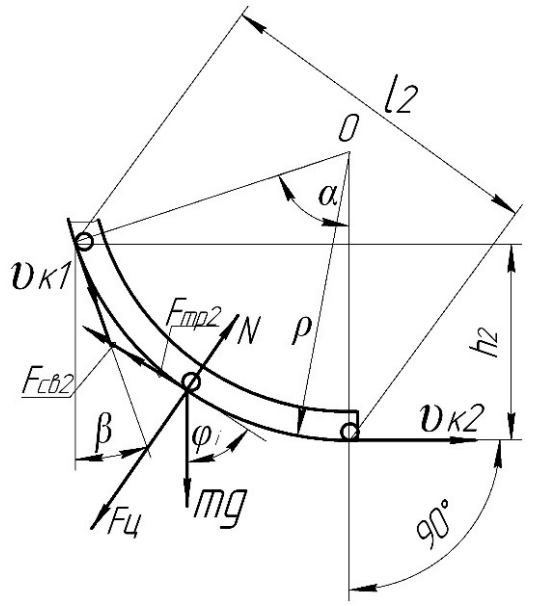

Fig. 3. Scheme of movement of the seed on the drill tube area II

Continuing movement on area III the seeds increase the speed due to the force of air stream $F_{6}$.

$$
F_{\theta}=m \cdot K_{\Pi} \cdot v_{B}^{2}=m \cdot a_{i},
$$

where $a_{i}$-air-flow acceleration of seeds, $\mathrm{m} \cdot \mathrm{s}^{-2}$.

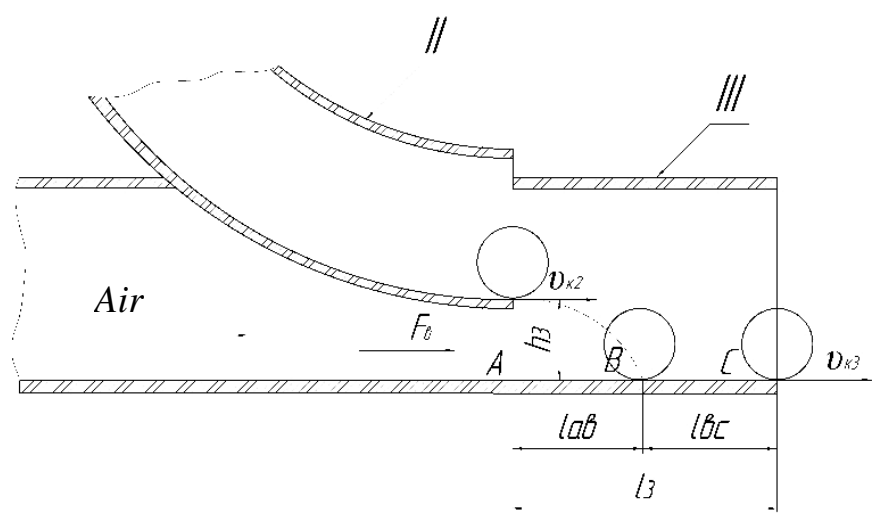

Fig. 4. Scheme of movement of the seed on the drill tube area III

The seed velocity at the end of the segment $\mathrm{AB}$ is determined by expression

$$
v_{a b}=v_{\kappa}+a t_{a b}=\frac{g v_{\kappa 2}+\sqrt{2 g h_{3}} \cdot K_{\Pi} \cdot v_{B}^{2}}{g},
$$


but the length $l_{a b}$ of the segment $\mathrm{AB}$ :

$$
l_{a b}=v_{\kappa 2} \cdot t_{a b}+\frac{a t_{a b}^{2}}{2}=\frac{v_{\kappa 2} \sqrt{2 g h_{3}}+K_{\Pi} h_{3} v_{B}^{2}}{g} .
$$

At the exit from the accelerator, the speed of seeds should be equal to the speed of the seeder, then the acceleration of seeds on the segment $\mathrm{BC}$ is equal to:

$$
a_{b c}=\frac{v_{a}-v_{a B}}{t_{b c}},
$$

where $v_{a}$-speed of the seeder, $\mathrm{m} \cdot \mathrm{s}^{-1}$.

The length $l_{s c}$ of the segment AB:

$$
l_{B c}=\frac{m\left(v_{a}^{2}-v_{a b}^{2}\right)}{2\left(F_{B}-F_{m p 3}\right)}=\frac{m v_{a}^{2}-m\left(v_{\kappa 2}+\frac{K_{\Pi} v_{b}^{2} \sqrt{2 g h_{3}}}{g}\right)^{2}}{2\left(K_{\Pi} m v_{B}^{2}-f \cdot N_{3}\right)} .
$$

The required parameter is the seed velocity at the exit from the accelerator $v_{k 3}$, then substituting the velocity $v_{\kappa 3}$ in formula (7) instead of $v_{a}$, we obtain a formula for determining the seed velocity at the exit from the accelerator:

$$
v_{\kappa 3}=\sqrt{2 K_{\Pi} l_{3} v_{\theta}^{2}+\left(v_{\kappa 2}+\frac{K_{\Pi} v_{\theta}^{2} \sqrt{2 g h_{3}}}{g}\right)^{2}-\frac{2 K_{\Pi} v_{\theta}^{2}}{g}\left(v_{\kappa 2} \sqrt{2 g h_{3}}+K_{\Pi} h_{3} v_{\theta}^{2}\right)} .
$$

As a seed material, the seeds of corn of the Krasnodarskii 382MV were used. Weighing of seeds was carried out on the scales ALC-210d4. Aerodynamic properties of corn seeds were determined on the sailing classifier PPK-VIM [6].

From the analysis process seeding row crops it follows that the condition of the smallest dispersion seed furrow along the seed is equal to the speed at the moment of exit from the vas deferens and the movement speed drills. In this connection, in a laboratory with two photoelectric sensors (Figure 5) the seed velocity was determined at the exit of the vas deferens with the accelerator. The position of the seed was determined when it blocked the beam from the radiator to the receiver. The sensors were adjusted via the control unit.

Experimental studies of the process of seed movement on the drill tube were performed on a laboratory installation shown in Fig. 5.

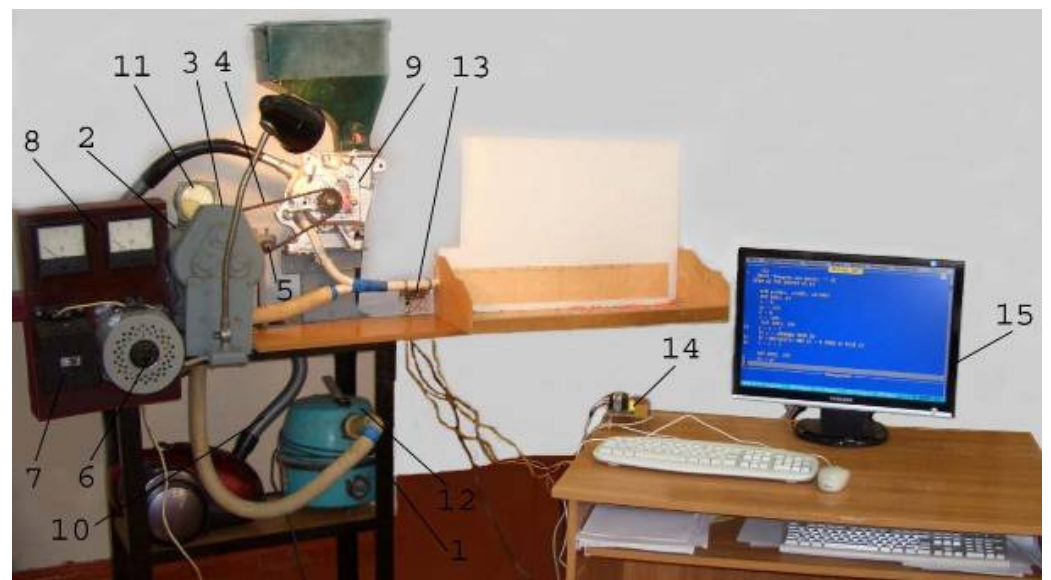

Fig. 5. Laboratory installation: 1 - frame; 2 - electric motor; 3 - reducer; 4 - chain; 5 - tension roller; 6 - voltage regulator; 7 - current rectifier; 8 - shield with control devices; 9 - seeder;

10 - vacuum unit; 11- diaphragm thimble Tm MP-100; 12 - air-inflating device with adjustable air supply; 13 - sensors for measuring of seed speed; 14 - control unit; 15 - personal computer 
The choice of the main factors affecting the rate of seeds at the exit from the drill tube with the accelerator was made on the basis of analytical and exploratory studies. From the theoretical studies it follows that the following factors influence the seed rate at the exit from the drill tube accelerator: $x_{1}$ is the speed of the air flow to the injection site; $x_{2}$ is the length of the accelerator; $x_{3}$ is the angular velocity of the sowing disk, $x_{4}$ is the radius of suction holes; $x_{5}$ - coefficient of friction of the seed in the drill tube; $x_{6}$ - coefficient of sailing of seeds; $x_{7}$ is the weight of the seed; $x_{8}$ is the length of the area I of the drill tube; $x_{9}$ is the angle of the seed from the sowing disk; $x_{10}$ is the radius of curvature of the area II of the drill tube; $x_{11}$ is the length of the area II of the drill tube.

The $x_{4}$ factor was determined from the geometrical parameters of the sowing disk and did not change during the experiments; $x_{5}, x_{6}, x_{7}$-determined experimentally and not included in the number of variable factors; Factors $x_{8}, x_{9}, x_{10}, x_{1}$ - are determined from the design features of the serial device of the seeder and taken as permanent.

The range of the factor $x_{1}$ is determined analytically and is $8-20 \mathrm{~m} \cdot \mathrm{s}^{-1}$. Accordingly, the main (zero) level of the factor $x_{1}$ is $14 \mathrm{~m} \cdot \mathrm{s}^{-1}$, and the variation interval is $6 \mathrm{~m} \cdot \mathrm{s}^{-1}$.

The range of variation $x_{2}$ is determined analytically, taking into account the constructive constraint. The interval of variation of the factor $x_{2}$ is set in the range $0.08-0.16 \mathrm{~m}$ with a basic level of $0.12 \mathrm{~m}$ and a variation interval of $0.04 \mathrm{~m}$.

The factor $x_{3}$ varies between $2-4 \mathrm{rad} \cdot \mathrm{s}^{-1}$. For the main level $x_{3}$, the value $3 \mathrm{rad} \cdot \mathrm{s}^{-1}$ is adopted with a variation interval of $1 \mathrm{rad} \cdot \mathrm{s}^{-1}$.

To carry out the three-factor experiment, a non-unique three-level Box-Bencin plan was chosen [7].

Determination of the qualitative indicators of the work of the improved sowing apparatus is performed in the field conditions.

\section{Results and discussion}

According to the research method, the properties of seeds necessary for carrying out experimental studies are determined: the mass of 1000 seeds is $0.31 \mathrm{~kg}$; the average speed of seed winding $v_{k p}=10.4 \mathrm{~m} \cdot \mathrm{s}^{-1}$; the coefficient of static friction of seeds on the surface of the drill tube was $f_{c m}=0.36$; the coefficient of dynamic friction of seed on the surface of the drill tube was $f=0.25$; the angle of friction of corn seeds in the drill tube is $22^{\circ} 14^{\prime} \pm 21^{\prime}$.

Analysis of the research results showed the actual average intervals between corn seeds when sowing with a pneumatic apparatus with a drill tube with an accelerator is $30.4 \mathrm{~cm}$, which is higher than the calculated step of sowing $(25.7 \mathrm{~cm})$. The coefficient of variation of the intervals between seeds of corn: the device with a drill tube and with the accelerator - 38.8. On the quality indicators, a seeder with an improved sowing device with an accelerator meets the requirements for the agrotechnical requirements for seeding, the percentage of seeds at intervals provided for by the initial requirements is $92 \%$. Using a seed pipe with an accelerator allows to control the process of seed delivery from the seeder to the bottom of the furrow with the seed feed rate of up to $3.5 \mathrm{~m} \cdot \mathrm{s}^{-1}$.

\section{Conclusions}

When sowing corn with a pneumatic drill with the speed of the unit more than $1.2 \mathrm{~m} \cdot \mathrm{s}^{-1}$, an oblique impact and rebound of seeds (more than $20 \mathrm{~mm}$ ) occur relative to the place of their fall. In order to avoid scatter of seeds, it is necessary to reduce the height and the angle of the seed drop, to change the magnitude and direction of their velocity at the moment of discharge, which is ensured by introducing into the design of the sowing apparatus a seed pipe with a seed accelerator.

The developed mathematical models allow to determine the speed of seeds at the exit from the I, II, III areas of the drill tube. The factors that make it possible to achieve the seed velocity at the exit from the drill tube, equal to the speed of the aggregate, are: the velocity of the air flow in the accelerator, the length of the accelerator, the angular velocity of rotation of the sowing disk.

The rational parameters of the sowing apparatus equipped with a drill tube with an accelerator are substantiated, and its operating regimes: the inner diameter of the drill tube $D_{\sigma H}=16 \mathrm{~mm}$, the height of the beginning and end of the sections $h_{1}=0.14 \mathrm{~m}, h_{2}=0.05 \mathrm{~m}, h_{3}=0.01 \mathrm{~m}$. The radius of curvature of 
the second area of the drill tube is $\rho=0.076 \mathrm{~m}$, the seed descent angle from the sowing disc $\beta=20^{\circ}$, the length of accelerator $l_{3}=0.12 \mathrm{~m}$, the rotational speed of the sowing disk $\omega=2.5-3.0 \mathrm{~s}^{-1}$, the air speed in the accelerator $v_{b}=18-20 \mathrm{~m} \cdot \mathrm{s}^{-1}$.

The experimental studies established that: the average intervals between maize seeds when sowing with a pneumatic apparatus with a vas deferens without an accelerator were $342 \mathrm{~mm}$, with a seed pipe with an accelerator of $304 \mathrm{~mm}$, which is higher than the calculated seeding step $(257 \mathrm{~mm})$; The coefficient of variation of the intervals between seeds for the above-mentioned vesicles was $41.4 \%$ and $38.8 \%$; The percentage of seeds with intervals provided by the initial requirements, respectively, equal to $52 \%$ and $92 \%$

\section{References}

1. Белодедов В. А. Рассеивание семян при пунктирном посеве (Dissipation of seeds in singlegrain sowing). Mechanization and electrification of agriculture Journal, vol. 11, 1986, pp. 16-19. (In Russian)

2. Зубрилина Е. М. Распределение семян двух культур в рядке при совместном высеве (Distribution of seeds of two crops in a row during joint sowing). Mechanization and electrification of agriculture Journal, vol. 7, 2002, pp. 13-15. (In Russian)

3. Исаев И. К. О сравнении равномерности распределения семян (Intercomparison of the uniformity of seed distribution). Mechanization of works in selection, variety testing of primary seed production Journal, Moscow, 1985, T. 106, p. 56. (In Russian)

4. Кошурников А.Ф. Пунктирный посев пропашных культур и формирование густоты насаждений: монография (Single-seed planting of row crops and formation of plantation density: monograph) - Perm: "Prokrost" CPI, 2015 - 218 p. (In Russian)

5. Василенко В.В. Совершенствование процесса формирования пунктирного ряда семян и растений пропашных культур: дис... докт. техн. наук. Воронеж, 2007. - 394 с. (Vasilenko V.V. Perfection of the process of formation of the single-seed row of seeds and plants of row crops: dis ... doc. tech. sciences. Voronezh, 2007. - 394 p.) (In Russian)

6. Фирсов М.М., Пышкин В.К. Анализ процесса пневмотранспортирования зерна методами математического моделирования (Analysis of pneumatic conveying process of grain by mathematical modelling methods). Tractors and agricultural machinery Journal, vol. 5, 2001, pp. 33-35. (In Russian)

7. Мельников С.В., Алешкин В.Р., Рощин П.М. Планирование эксперимента в исследованиях сельскохозяйственных процессов (Planning of the experiment in research of agricultural processes). Moscow, 1980, 168 p. (In Russian) 